\title{
PUSHING THE BOUNDARIES OF POSTGRADUATE SUPERVISION
}

\section{THEORISING RESEARCH LEARNING IN COMMUNITY}

\section{Callie Grant}

\section{BACKGROUND AND CONTEXT}

In keeping with global trends, there is a national imperative in the terrain of higher education in South Africa to increase the percentage of university students studying at the postgraduate level (RSA DHET 2012). With this comes mounting pressure to increase the throughput rates of postgraduate students in the country's universities for economic, social and political reasons, and critically in order to maintain and further what has become known as the 'knowledge project'. However, as a result of the inequities of the apartheid era, the higher education arena is faced with a complex and diverse student population (Quinn 2012) and ever-increasing student numbers (Snowball \& Sayigh 2007) as it attempts to grapple with issues of epistemological access, redress and quality. To date, there is evidence to suggest that our higher education system is failing the majority of students, at both the undergraduate and the postgraduate levels (Letseka \& Maile 2008; Scott, Yeld \& Hendry 2007). Higher education in South Africa, therefore, must be understood to speak to both the 'knowledge project' and the issue of social justice, as without a sustained emphasis on the latter, the country will have failed in its mandate to engage in equal and equitable transformation of the higher education system.

Against this backdrop and ideological position, this chapter emerges out of my experience of teaching and supervising several cohorts of postgraduate students at the master's level in the field of Educational Leadership and Management (ELM) over a number of years. In particular, it draws on research based on three South African case studies of ELM research learning in community; the first two at the Honours' level and the third at the Masters' level. Data were drawn from course evaluations, student reflective journals, a focus group interview with students as well 
as official documentation such as pass rates, throughput rates, examiners' reports and supervisors' reports.

In South Africa the Master of Education (MEd) qualification is offered as either coursework/half-thesis or full thesis and, for the purposes of this chapter, the focus is on the coursework/half-thesis offering. The chapter has arisen from a concern that although many students successfully complete the coursework component of the MEd degree in the required time, the majority spends far too much time in trying to complete the half-thesis component and many do not complete at all (see also Grant 2013; Letseka \& Maile 2008; Sayed, Kruss \& Badat 1998 in this regard).

There may be three key reasons for this low throughput rate. Firstly, the MEd (ELM) student body is 'non-traditional' in that very few 'young' students enter the programme having followed a direct undergraduate degree, followed immediately by an Honours degree. The majority of students who enter a MEd (ELM) programme in the South African context comprise mature-aged professionals who elect to study on a parttime basis because they hold down permanent employment in schools, Department of Education offices or in education non-governmental organisations. Many of the professionals who register for these qualifications hold formal management positions in their places of work and consequently hold in balance, sometimes precariously, responsibilities related to their careers, their extended families as well as their further studies. The second reason for this low throughput rate is a consequence of South Africa's apartheid history which has resulted in students arriving at the academy with a diverse and complex array of domestic, cultural, linguistic, educational and economic capital. This range of capital inevitably presents a multitude of social and intellectual challenges in the teaching and learning processes. A final reason for this low throughput rate is that the majority of these students have little prior experience of the academic discourses in the field of ELM and neither have they been involved in research and thesis writing prior to their embarking on the MEd (ELM) qualification.

Taking the above into consideration, and holding the desire for a socially just and equitable education experience for all students as a primary goal, experience has shown that it is almost impossible for the majority of these part-time ELM students to complete the degree in the minimum number of academic study years legislated. Only in rare cases does this happen and yet, in practice, the degree remains structured as a two year offering for part-time study at the majority of higher educational institutions in our country. This sets up the unrealistic expectation that the degree ought to be completed within this period. Our responsibility as higher education professionals is therefore to challenge this discriminatory practice whilst 
simultaneously searching for ways to support the research learning of these students so that they ultimately reach the exit level required.

A key point of departure is to acknowledge that these MEd students are novices in the arena of research and that they require a process of induction into the academic enterprise, a view endorsed by Sayed et al. (1998). Our work, as legislated in the Higher Education Qualifications Framework (HEQF) is therefore to educate and train these novice researchers in order that they can ultimately contribute to the development of knowledge (RSA 2007:27, my emphasis). This requires a fundamental shift in our thinking about postgraduate teaching and supervision. It calls for a scholarship of teaching within the supervision process and challenges us to think creatively about the pedagogy of research learning. Research learning in this conceptualisation refers to the "domain of learning which novice researchers (such as postgraduate students) experience in the complex process of learning to become a researcher" (Jansen, Herman \& Pillay 2004:79).

A strategy to strengthen the learning of research and, in so doing, push postgraduate supervision boundaries, is through the establishment of a community of practice at the MEd level with a focus on research learning. This community of practice is one in which novice researchers are supported and enabled in acquiring the knowledge and capabilities necessary for successful postgraduate study. It requires rigorous teaching within a shared, systematically organised 'pedagogical space' (Boud \& Lee 2005) and inevitably stands "in contrast to the conventional focus on individual supervision relationships as the privileged if not the only acknowledged site of pedagogy" (Boud \& Lee 2005:503). While there is a growing body of literature on research learning in community at the doctoral level in South Africa (see for example Jansen et al. 2004; Lotz-Sisitka, Ellery, Olvitt, Schudel \& O'Donoghue 2010), little has been written about this approach to supervision at the master's level. Thus the purpose of this chapter is to challenge us to think differently about supervision at the master's level and, to this end, I draw on the work of Alan Fiske $(1991,1992)$ to reimagine the $\mathrm{MEd}$ pedagogical space.

\section{REIMAGINING PEDAGOGICAL SPACE: LEARNING IN COMMUNITY}

In theorising research learning and student success at postgraduate level, I take the position that the liberal notion of supervision with its traditional one-to-one relationship between student and supervisor can no longer be considered the only option in the higher education arena in South Africa. This is not to say that individual supervisor-student interaction does not still play a central role in research learning and development, only that it need no longer drive the structure and organisation of 
postgraduate supervision. Rather, a communal approach to postgraduate supervision is a beneficial alternative given the diverse and complex society in which we live, and the possible opportunities this diversity can provide in expanding and enriching the teaching and learning process. Thus, I believe that the supervision process can be greatly enhanced if it is conceptualised as relational within a scholarly community of practice (Wenger 1998). While Wenger's conceptualisation of community has been well critiqued (see for example Hodkinson \& Hodkinson 2004; Maistry 2008), it remains important as a starting framework to the social learning processes and hence to the processes of research learning.

As ELM lecturer and supervisor, I foreground my role as teacher in the research and supervision process and consciously construct each new postgraduate group as an opportunity to support scholarly learning and knowledge generation in a community of practice. In this conceptualisation (after Wenger 1998), learning is understood as a social phenomenon where people - a diverse cohort of postgraduate students relate to each other and participate actively in a practice through mutual engagement in the joint enterprise of research learning. Here the learning is not limited to the knowledge and technical competence required for completion of the thesis but extends beyond this to include "the emotional, social, political and cognitive experiences that together constitute such learning" (Jansen et al. 2004:80).

In determining how students relate to one another within this research learning community, I draw on the relational models theory of Fiske $(1991$, 1992). Fiske, an anthropologist working in the field of cultural psychology, argues that people across cultures are fundamentally sociable and "generally organise their social life in terms of their relations with other people" (1992:689). His theory explains social life as a process of "seeking, making, sustaining, repairing, adjusting, judging, construing, and sanctioning relationships" (Fiske 1992:689).

Fiske identifies four basic types of elementary social relationships which he believes people in all cultures use to generate most kinds of social interaction, evaluation and affect. He refers to these four relationships as communal sharing (cs), authority ranking (ar), equality matching (em) and market pricing ( $\mathrm{mp}$ ). Fiske works from the premise that people generally want "to relate to each other, feel committed to the basic types of relationships, regard themselves as obligated to abide by them, and impose them on other people (including third parties)" (1992:689). In the context of postgraduate supervision, Hugo (2012) has taken these four relationship types and applied them to the postgraduate supervision process, arguing that they help to illuminate some of the basic patterns of supervision. 
Building on Hugo's (2012) ideas about the application of Fiske's relational models theory to the supervision process I have found the four relationship types pertinent to my own work around teaching and supervision within the community research learning approach. To this end, the next section of the chapter works with Fiske's four types of elementary social relationships as they apply to the community research learning approach.

\section{APPLYING RELATIONAL MODELS THEORY TO THE COMMUNITY RESEARCH LEARNING APPROACH}

\section{Communal-sharing relationships}

In relation to the postgraduate supervision process and in a conscious attempt to increase throughput rates whilst ensuring quality, each newly registered MEd (ELM) cohort is immediately set up as a structure to support novice researchers in the research learning process. The size of the cohort varies depending on supervision capacity within the faculty and success rates in the application process but, on average, a cohort of 12 MEd (ELM) students and three to four supervisors works well. The research learning community meets regularly throughout the two-year period of the MEd degree; it is guided by a clearly articulated purpose and follows a programme which includes a range of activities with a series of submission deadlines. In this conceptualisation, the coursework component of the degree is not perceived as an individual entity, disconnected from and preceding the development of the half-thesis. Instead it becomes reconceptualised as "integral to, and interwoven with, the research component and structured in ways which enable research and support the growth and development of the half thesis from the onset of the degree" (Grant 2013:1255).

Immediately after the establishment of the research learning community, 'communal sharing' relationships (Fiske 1991) are foregrounded within the group. Communalsharing relationships, Fiske explains, "are based on a conception of some bounded group of people as equivalent and undifferentiated" (1992:690). In this type of relationship, Fiske contends, the focus is on the commonalities in the group rather than on distinct individual differences. Thus, in the initial stages of the research learning community, I consciously downplay the individual differences amongst the students and instead concentrate on making explicit the existing commonalities. These include factors such as they are all experienced educators, they have all been selected for the qualification, they are all novice researchers and they all have experience of educational leadership and management in the workplace. As 
a consequence of these commonalities, the students realise that they are similar in many respects and this shared experience is used to draw the group together.

I begin my teaching by intentionally encouraging the sharing of experiences and ideas in the form of everyday knowledge of educational leadership and management with which the students inevitably arrive. This everyday knowledge, sourced from the mass media or from the workplace, is a form of horizontal discourse which is "oral, local, context dependent and specific, tacit, multilayered and contradictory across but not within contexts" (Bernstein 2000:157). This tacit knowledge of leadership and management provides a useful starting point to the research learning process. Involvement of all participants is crucial in any research learning community and eliciting, sharing and opening this tacit knowledge out to interrogation is an important first stage in the induction process. Sharing of this tacit knowledge immediately draws the novice researchers into a relationship of communal sharing as does participating in the programme and committing to its purpose.

A further attempt to encourage sharing and develop communal-sharing relationships among the group is the sharing of material resources such as academic articles and books, notes, summaries as well as meals. These resources are shared according to need and, as Fiske explains, "simple membership in the group is sufficient to entitle one to the use of whatever resources the group controls, and long-run imbalance is not a violation of the relationship" (1992:693). As a bond begins to develop among members of the group, individuals begin to share their expertise which may be in the form of assistance in relation to library searches and the use of information technologies, for example. Other forms of sharing include the sharing of ideas and feedback during peer and lecturer learning processes (see Grant 2013), offered in a spirit of kindness and encouragement.

\section{Authority-ranking relationships}

'Authority ranking' is a second type of social relationship in Fiske's relational models theory. According to Fiske, authority ranking is based on a model of "asymmetry among people who are linearly ordered along some hierarchical social dimension" (1992:691). Authority ranking is a social reality and it is a dominant feature of a research learning community.

When educational professionals join the diverse community of postgraduate students in their particular degree cohort, they arrive with a lived experience of the hierarchical power relations of the schooling terrain. They are likely to assess how they stand in relation to the others in terms of their educational status (i.e. whether they are a principal, a head of department or a post level 1 teacher), their gender 
and age. In this regard, I deliberately adopt a range of strategies to diffuse the power differentials within the group. Within a short space of time, students realise that gender, age and professional ranking of the schooling system have little value in the research learning community where the focus is on the development of their scholar/ researcher identity. Instead, what becomes important is the value each individual, regardless of gender, age or designation, contributes to the academic endeavour at any given time.

However, authority-ranking relationships do not only exist among the students. Relationships of power also exist between students and supervisors. As a consequence of institutional position and "epistemic credibility" (Fataar 2012:17) derived from field knowledge, academics command legitimate authority in a research learning community. Epistemic credibility is absolutely crucial to the teaching and supervision process and novice researchers join the academy particularly to draw on and learn from this expertise. Thus the relationship between students and supervisors is asymmetrical and, particularly in the initial stages, the relationship constitutes a relatively high power distance index (borrowing from Hofstede 1980). Within this linearly ordered relationship of power, it is the supervisor who takes on a pastoral responsibility and the students who defer to the seniority of the supervisor "in exchange for guidance and induction into how knowledge and the academic community work" (Hugo 2012:109). Over time and with increased participation in the community, the power distance between student and supervisor gradually decreases as the student begins to develop an academic voice and a researcher identity.

\section{Equality-matching relationships}

As a consequence of 'getting to know each other' and 'doing things together' in the communal-sharing relationships, educational professionals begin a trajectory inwards from the periphery of the ELM community, gradually extending their repertoire of knowing (both in relation to the knowledge field itself as well as to associated research processes) and developing their identity and agency as ELM scholars and researchers. Within this pedagogical space, turn-taking is crucial to ensure that each person gets an equal chance to contribute. As Waghid elaborates, "every person wants to be recognised as someone with the same basic moral worth as any other participant - that is, as a person who has something to say and wants to be heard" (2012:43).

In the community research learning approach, turn-taking is fundamental to teaching, learning and assessment as in, for example, the delivery of seminar presentations, the posing of scholarly questions and the giving of feedback (see Grant 2013 for 
more elaboration). At a more mundane level, turn-taking is also evident in the provision of communal lunches at contact sessions which take place on a rotational basis and which further build the sense of friendship and community. Turn-taking ensures what Fiske (1992) refers to as 'equality matching' relationships where each person is entitled to the same amount of time, input, feedback and resources so that equality and balance within the community is ensured. By virtue of equality-matching relationships within the community, each student becomes a visible presence with a right to turn-taking and the accompanying responsibility it involves. Each becomes bound by an unwritten contract to contribute equally to the community and this requisite involvement leaves little space for individuals to get left behind or drop out.

While equality and balance through turn-taking are important in the community research learning approach, what is even more critical is the culture of mutual respect, valuing and trust that must be created and in which the turn-taking takes place. The approach is premised on the idea that each individual in the group is competent and capable to participate in the discussions and activities. 'Respect for persons' (following Waghid 2012) is consciously taught and modelled and students are valued for their contributions made in the deliberation. They are also challenged to substantiate their claims with evidence acceptable within the traditions of the academy. Within the community, lecturers/supervisors lead a discussion in which they acknowledge that they do not know everything there is to know in the field and explain that they too are on a learning trajectory in much the same way the students are, merely a little further along in their learning.

To further build trust and respect, pedagogical spaces are created which involve the co-construction of aspects and activities of the course. Examples of this coconstruction include the formulation of assignments, the setting of meeting and submission dates, the preparation of criteria for seminar assessment and the development of a protocol for generative participation in the community. In this secure environment, it is anticipated that these educational professionals will begin to develop an informed academic voice and participate equally in knowledge debates relevant to the field of ELM. My argument, following Ranson (2000:268), is that by developing their academic voice, these professionals will "find an identity and the possibility of agency in the world". Thus the community, through the equality-matching relationships, becomes one which recognises different voices and promotes genuine conversation as people learn "through dialogue to take a wider, more differentiated view, and thus acquire sensitivity, subtlety and capacity for judgement" (Ranson 2000:275). As these professionals become familiar with each 
other over time, they learn to respect the freedoms of others and, as Waghid (2012) rightly contends, friendships are engendered.

\section{Market-pricing relationships}

Initially, within the community research learning approach, it is the communalsharing, authority-ranking and equality-matching relationships that drive the new learning. However, it soon becomes evident that these three relationships are insufficient on their own because students need to be individually rewarded for the value they bring to the community and the amount of work they do. This brings to the fore the relationship of 'market pricing' which, Fiske explains, is based on "a model of proportionality in social relationships; people attend to ratios and rates" (1992:692). What matters in this type of relationship, he argues, is how a person stands in relation to others. It works on variations in the relationships which adjust according to specific forces encountered.

Market-pricing relationships are crucial in the research learning community because they attribute value to individuals, at any given time, in proportion to the amount of effort they put into their work and the quality thereof. Hugo (2013:125) explains that in the context of education, market-pricing relationships capture the "continual process of professional judgement a teacher is engaged in where relative values of what students are doing change all the time, resulting in different judgements at different times based on the situation at hand".

Particularly in relation to the coursework component of the MEd (ELM) degree, professional judgments are continually being made regarding students' work. Each student is rewarded for the quality of work done in each assessment task, whether it is formative or summative. In this regard, the use of an assessment rubric typically outlines what is expected from students and offers a common measure against which the quality of each individual piece of work is judged. This form of assessment against a common measure is a commonplace example of market pricing within the higher education terrain.

However, market pricing is also evident in the social spaces of the group and may emerge spontaneously as individual students contribute something of particular value to the group. For example, a student might be approachable, warm and driven by a social justice consciousness. She might be the one to whom a struggling student turns when challenged by a difficult concept in an academic article. This student might informally mediate the learning for the other person, either during or following the contact session. In this scenario, the value this student brings to the group is high and it surpasses that of the other students. Another student might add value to the 
learning process because she has a lively sense of humour and an infectious laugh which contributes to a safe and relaxed pedagogical space for all in the group. Yet another student might stand out because she takes the lead at the level of the social in holding the group together. She might be responsible for developing the group identity through organising social events, designing a group t-shirt or arranging a group photo-shoot. Yet another student might add value to the group because of her exciting intellectual debates and challenging questions. She might be unrelenting in her quest to understand and be unafraid to challenge the status quo.

While market-pricing relationships are applicable among students in the community research learning approach, they also have purchase among supervisors. In a community research learning approach, it is unlikely that there will only be one lecturer/supervisor. As mentioned earlier, a number of supervisors may be involved in supporting the learning process, depending on supervisor availability and the number of students in the cohort. It is very likely that each supervisor will take on a different role within the community, determined by factors such as "her academic expertise in the student's area of study, her research and publications record, her knowledge of the relevant literature, and her knowledge and expertise in the appropriate methodological approaches" (Fataar 2012:17). Thus supervisors bring to the supervision process differing levels of experience and expertise and they are sometimes driven by different value sets. This market pricing of supervisors can become an obstacle to the community research learning approach when students fight for access to the supervisor with the highest market pricing and the most impressive lineage (after Hugo 2012) at the expense of less experienced supervisors. Thus supervision within a community research learning approach is complex and requires further deliberation beyond the scope of this chapter. Suffice to say that the mentoring of supervisors into the community approach is crucial in order to guard against uneven supervisory support. Equally important is the critique which the supervisory team brings to the research agenda and which can offer a necessary counter-voice to the lead supervisor and reduce the risks associated with lineage and potential cloning of students.

\section{LEARNING IN COMMUNITY: MOVING CONFIDENTLY TOWARDS CENTRAL PARTICIPATION}

In the chapter thus far I have used the four types of elementary social relationships associated with Fiske's $(1991,1992)$ relational models theory to help me describe and explain the central facets of research learning of novice researchers within a community learning approach. I have demonstrated how the four relationships of 
communal sharing, authority ranking, equality matching and market pricing are useful in illuminating some of the basic relationship patterns of supervision within a research learning community. However, the argument is incomplete as it stands without some discussion of how these relationships contribute to what Wenger refers to as "changing participation and identity transformation in a community of practice" (1998:11). To ensure changing participation and identity transformation, I argue that the development of confidence is a central feature of this research learning process. Here I draw on the work of Graven who asserts that "confidence is part of an individual teacher's ways of learning through experiencing, doing, being, and belonging. As such it is deeply interconnected with learning as changing, meaning, practice, identity and community" (2004:179).

Thus, through the relationships of communal sharing, authority ranking, equality matching and market pricing experienced during the interplay of learning processes (peer-, self- and lecturer-initiated) (see Grant 2013) within the research learning community, the novice researchers begin to develop confidence. This level of confidence increases over time as each student becomes progressively more proficient as both "a user of various specialist discourses and a participant within the relevant knowledge communities" (Northedge 2003:22). As the individual capacity of each student is affirmed, they grow in confidence and embark on a journey from the periphery of the research learning community "towards more central participation, identification and belonging" (Graven 2004:208). This journey in confidence culminates in the student being able to "adopt a stance, a theoretical framework, or language that they use to 'gaze' upon the world" (Bernstein 2000:164).

It stands to reason that as students develop in confidence over time, they will rely increasingly less on the support drawn from communal-sharing relationships. With increased confidence, dependence on supervisors will also decrease and the student/supervisor relationship will move towards a low power distance index (again borrowing from Hofstede 1980). Thus, as the supervisory relationship comes to term, balance is established when the student "takes on the mantle of independent researcher doing her own work in her own voice" (Hugo 2012:109). In this way, equilibrium in the student-supervisor relationship is achieved as students move towards full membership of the field.

\section{CONCLUDING COMMENTS}

The complex and diverse terrain of higher education in South Africa today demands that we think afresh about our pedagogy and supervision strategies if we are to improve the number and quality of passes as well as student throughput rates at 
both undergraduate and postgraduate levels. Against this backdrop, the focus of this chapter has been the MEd degree in ELM and particularly the coursework/half-thesis offering. The chapter has arisen out of a concern that many students spend far too long trying to complete the half-thesis component of the degree and some do not complete at all.

In response to this crisis, I have advocated that the traditional one-to-one supervisory relationship can no longer be considered the only option in the higher education arena in South Africa. This is primarily because the one-to-one supervision model reflects a Western preoccupation with the individual and, as such, is limited to the research learning of one student via one supervisor to the exclusion of other sources of research learning. Thus, and given the national imperative to increase the percentage of university students studying at postgraduate level, this model is fast becoming inefficient, costly and inappropriate for the South African context.

In contrast to the Western focus on the individual, South Africa's philosophical heritage hinges on the consciousness of human interconnectedness and interdependence and, as Ramphele (2008) contends, this philosophy has been imbedded in the conduct of African social relationships from time immemorial. Perhaps the time is right to bring to life this philosophy in our teaching, learning and supervision practices within the postgraduate terrain. One such way, I have argued, is to draw on social learning theory and adopt a communal approach to postgraduate supervision. This collective approach foregrounds the pedagogy of research learning, it creates the space for a diversity of views and voices to be heard and it provides structured support in an expanded and enriched teaching and learning process.

Thus the community research learning approach offers students a network of social relationships within which to learn about and do research and Fiske's $(1991,1992)$ work on relational models theory is pertinent here. His four types of social relationships (communal-sharing, authority-ranking, equality-matching and marketpricing) are useful in describing and explaining the relationships inherent in the various pedagogical practices as novice researchers engage in the research learning process and begin a trajectory inwards towards the centre of the practice. These four social relationships offer what Hugo (2012) refers to as an orientating device which helps one to steer a course in the complex pedagogic space of postgraduate study. But these four relationship types are insufficient on their own without some focus on the pivotal role of confidence (after Graven 2004) in our understanding of research learning in the trajectory towards more central participation, identification and belonging. 
In closing, I believe that adopting a community researching learning approach in our postgraduate work has the potential to increase both the quality of student passes and student throughput rates while also offering a transformative learning experience for postgraduate students. As such, it can make a contribution to the country's social justice agenda. In this way, I argue that as we continue to theorise postgraduate supervision, the approach will push the boundaries of postgraduate work, particularly at the MEd level, beyond their current location.

\section{ACKNOWLEDGEMENTS}

This chapter would be incomplete without acknowledging two cohorts of MEd students I was fortunate to work with from 2008 to 2011 . Their commitment to the academic project was a source of inspiration to me. In addition, a number of colleagues have read earlier drafts of this chapter and made valuable comments: Professors Wayne Hugo, Aslam Fataar, Chrissie Boughey, Hennie van der Mescht, Dr Carol Thomson and Ms Farhana Kajee.

\section{REFERENCES}

Bernstein B. 2000. Pedagogy, symbolic control and identity: Theory research, critique. Second edition. Oxford: Rowman and Littlefield.

Boud D \& Lee A. 2005. 'Peer learning' as pedagogic discourse for research education. Studies in Higher Education, 30(5):501-516.

Fataar A. 2012. Negotiating student identity in the doctoral proposal development process: A personal reflective account. In: A Fataar (ed). Debating thesis supervision. Stellenbosch: SUN MeDIA. 13-35.

Fiske AP. 1991. Structures of social life: The four elementary forms of human relations. New York: The Free Press.

Fiske AP. 1992. The four elementary forms of sociality: Framework for a unified theory of social relations. Psychological Review, 99(4):689-723.

Grant C. 2013. Using assessment strategically to gestate a student thesis: Learning through community. South African Journal of Higher Education, 27(5):1250-1263.

Graven M. 2004. Investigating mathematics teacher learning within an in-service community of practice: The centrality of confidence. Educational Studies in Mathematics, 57:177-21 1.

Hodkinson P \& Hodkinson H. 2004. A constructive critique of communities of practice: Moving beyond Lave and Wenger. Seminar paper presented at the Integrating Work and Learning - Contemporary Issues Seminar Series, University of Technology, Sydney, 11 May.

Hofstede G. 1980. Motivation, leadership and organisation: Do American theories apply abroad? Organisational Dynamics, 9(1):42-63.

Hugo W. 2012. Supervision response. In: A Fataar (ed). Debating thesis supervision. Stellenbosch: SUN MeDIA. 107-113. 


\section{PART FOUR • SUPERVISION STRATEGIES}

Hugo W. 2013. Cracking the code to educational analysis. Cape Town: Pearson.

Jansen J, Herman C \& Pillay V. 2004. Research learning. Journal of Education, 34:79-102.

Letseka M \& Maile S. 2008. High university drop-out rates: A threat to South Africa's future. Pretoria: HSRC.

Lotz-Sisitka H, Ellery K, Olvitt L, Schudel I \& O’Donoghue R. 2010. Cultivating a scholarly community of practice. Acta Academica Supplementum, 1:130-150.

Maistry SM. 2008. Transcending traditional boundaries for teacher professional development: Exploring a community of practice approach to CPD. Journal of Education, 43:127-153.

Northedge A. 2003. Rethinking teaching in the context of diversity. Teaching in Higher Education, 8(1):17-32.

Quinn L. 2012. Understanding resistance: An analysis of discourses in academic staff development. Studies in Higher Education, 37(1):69-83.

Ramphele M. 2008. Laying ghosts to rest: Dilemmas of the transformation in South Africa. Cape Town: Tafelberg.

Ranson S. 2000. Recognising the pedagogy of voice in a learning community. Education Management and Administration, 28(3):263-279.

RSA (Republic of South Africa). 2007. The Higher Education Qualifications Framework. Government Gazette, 5 October. Pretoria: Department of Education.

RSA DHET (Republic of South Africa. Department of Higher Education and Training). 2012. Green Paper for Post-school Education and Training. Pretoria. [Accessed 12 January 2013] www.info.gov.za/view/downloadFileAction?

Sayed Y, Kruss G \& Badat S. 1998. Students' experience of postgraduate supervision at the University of the Western Cape. Journal of Further and Higher Education, 22(3):275-285.

Scott I, Yeld N \& Hendry J. 2007. Higher Education Monitor No. 6. Pretoria: Council on Higher Education.

Snowball JD \& Sayigh E. 2007. Using the tutorial system to improve the quality of feedback to students in large class teaching. South African Journal of Higher Education, $21(2): 321-333$.

Waghid Y. 2012. Education, responsibility and democratic justice: Cultivating friendship to alleviate some of the injustices on the African continent. In: A Fataar (ed). Debating thesis supervision. Stellenbosch: SUN PRESS. 37-55.

Wenger E. 1998. Communities of practice: Learning, meaning and identity. Cambridge: Cambridge University Press. 